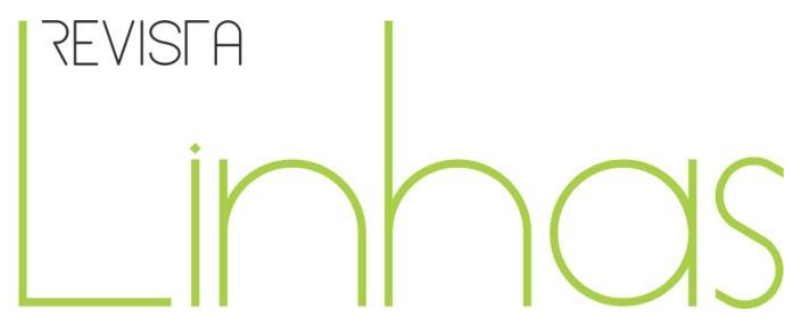

\title{
A criança, a educação e o brincar no processo de colonização de Sinop - MT (1973-1979)
}

\section{Resumo}

Este artigo direciona um olhar para a criança, para a produção cultural do brincar e para a educação de Sinop, cidade localizada ao Norte de Mato Grosso, colonizada na década de 1970. O ensejo é sinalizar para uma questão emergente na História da Educação para o que diz respeito ao papel histórico, cultural e social da criança no passado, entendida desta forma como ator/atriz social, produtor/a de cultura e história. Reconhecemos na cultura infantil pro-duzida pelos sujeitos 'crianças do passado' a possibilidade de concebermos a história de um cotidiano marcado pela criação, invenção e reinvenção daquilo que os sujeitos faziam com os produtos que lhes eram fabricados (CERTEAU, 1998). Procuramos iniciar uma caminhada para um olhar para a História da Infância, que conceba as crianças como coautoras da história, participantes ativas na construção da cultura juntamente com os adultos e entre seus pares, de forma a possibilitar a visibilidade social da criança na história e seu papel na sociedade. Para tal, metodologicamente a pesquisa histórica utilizou-se de iconografias, documentos escolares, decretos, legislações da época, cadernos escolares e depoimentos orais.

Palavras-chave: Infância - História. Educação de Crianças. Colonização. Brincadeiras. Educação - História - Mato Grosso.

\section{Para citar este artigo:}

ROHDEN, Josiane Brolo; DE OLIVEIRA, Emilene Fontes. A criança, a educação e o brincar no processo de colonização de Sinop - MT (1973-1979). Revista Linhas. Florianópolis, v. 19, n. 40, p. 307-330, maio/ago. 2018.

\author{
Josiane Brolo Rohden \\ Universidade Federal de \\ Rondônia - UNIR - \\ Vilhena/RO - Brasil \\ josirohden123@gmail.com \\ Emilene Fontes de Oliveira \\ Universidade Federal do Mato \\ Grosso - UFMT - Cuiabá/MT - \\ Brasil \\ emilenef29@gmail.com
}




\title{
The child, the education and the play in the process of coloni- zation of Sinop-MT (1973-1979)
}

\begin{abstract}
This article directs to the child, to cultural production of the play and to the education of Sinop, a city located North of Mato Grosso State, colonized in the 1970. The opportunity is to indicate to the emerging question on history of education for the historical, cultural and social role of the child in the past, understood in this way as social actor/actress, producer of the culture and history. We recognize in the child culture produced by subject 'children of the past' the possibility of conceiving the history of a daily life marked by creation, invention and reinvention of what the subjects did with the products they were produced (CERTEAU, 1998). We search to start a walk for a look at the history of childhood, to conceive children as co-authors in history, active participants in the construction of culture along with the adults and among their pairs, in order to enable the visibility of children in social history and your role in society. So, methodologically this historical research used Iconographies, school documents, decrees, and laws of the time, school notebooks and oral evidences.
\end{abstract}

Keywords: Childhood - History. Children Education. Colonization. Play. Education - History - Mato Grosso. 


\section{Apresentação}

Este artigo direciona um olhar para as crianças enquanto produtoras de história e cultura, como participantes do processo de colonização da cidade de Sinop-MT, algo que a História Oficial não pontua, uma vez que elas (as crianças) configuravam o espaço em estudo, eram levadas às ruas para desfiles cívicos ou para receber alguma autoridade, ajudavam nas funções sociais e privadas das famílias e era nelas que o ‘futuro' estava depositado pela sociedade, mas, no entanto, não receberam a devida visibilidade histórica-social, sendo percebidas na História Oficial apenas como figurantes e não coautores/as da história.

Por conceito de "culturas da infância”, entende-se com Sarmento (2003, p. 3-4) "a capacidade das crianças em construírem de forma sistematizada modos de significação do mundo e de ação intencional, que são distintos dos modos adultos de significação e ação". Essa concepção de culturas da infância é oposta às representações que, segundo Ariès (1981), durante muito tempo imperavam, uma vez que a criança, na Idade Média, não ocupava lugar de evidência e era concebida como um ser que poderia ser substituído, possuindo um papel utilitário na sociedade.

Desta forma, o ensejo é destacar uma questão relevante para História da Educação - o de ressignificar a História da Infância construída ao longo do tempo concebendo então, o papel histórico, cultural e social da criança no passado, entendida desta forma como ator/atriz social, sujeito produtor/a de cultura e história.

Contudo, este trabalho está organizado em quatro momentos. Na primeira ocasião, contextualizamos o processo de colonização da cidade de Sinop, pontuando a temporalidade pelo início do processo colonizatório (1973), delimitando ao ano de 1979, ano este em que a cidade se torna município e, então, ocorrem mudanças político-sociais significativas, as quais modificam, portanto, o cenário em estudo.

No segundo momento, apresentamos a constituição da primeira Instituição escolar de Sinop, construída pela iniciativa dos próprios migrantes, que quando chegaram ao local se depararam com a ausência da escola, ou seja, a realidade encontrada pelos primeiros migrantes era contrária à divulgação publicitária anunciada no Sul do país que 
incluía a educação como ferramenta de atração dos migrantes para o Norte de Mato Grosso.

Na conjuntura seguinte, pontuamos a organização escolar bem como as práticas educativas e de escolarização que ocorriam no cotidiano da escola em análise. Destacando fontes documentais encontradas na escola, cadernos escolares de ex-alunos, assim como depoimentos orais de como ocorria o processo educativo.

Por fim, enfatizamos o brincar enquanto produção histórica, social e cultural da infância, a auto-organização da infância no recreio escolar, os modos de fazer que as crianças encontravam para utilizar-se das táticas próprias que driblavam as estratégias do lugar da ordem e do poder (CERTEAU, 1998), fazendo deste modo com os produtos que Ihes eram fabricados, um lugar praticado (idem).

Contudo, intenta-se neste trabalho ampliar a discussão na História da Infância no que se refere à produção cultural da infância, compreendendo que as crianças apropriamse de forma criativa da informação do mundo adulto para produzir sua própria cultura, apropriação esta que é um processo de criação, de produção interpretativa, inventiva e, sobretudo, sensível aos modos da infância.

\section{O processo de colonização de Sinop - MT}

Na década de 1970, a região Norte de Mato Grosso passou por um processo acentuado de migração. Muitos migrantes, principalmente do Sul do Brasil, em especial pequenos produtores de terra, deixaram suas cidades de origem, para "ocupar" os espaços ditos "vazios"1 das terras norte mato-grossenses, em busca de maiores oportunidades, de um futuro promissor, diferente de como viviam em sua terra natal, marcada por fortes geadas e pelas dificuldades que encontravam frente aos grandes latifundiários que se expandiam.

\footnotetext{
${ }^{1}$ Faz-se necessário pontuar que o Governo Militar da época possuía como slogan político: “Ocupar para não entregar”, se referindo à ocupação dos espaços denominados "vazios” na Amazônia, como estratégia de "ocupar economicamente" tais espaços. Neste contexto, o Norte do estado de Mato Grosso que era ocupado por índios, extrativistas, posseiros e seringueiros, passou a ser ocupado por migrantes vindos principalmente do Sul do país (SOUZA, 2012).
} 
Desde o Governo Getúlio Vargas, com o chamado projeto Marcha para Oeste 2 , que visava ocupar e desenvolver o interior do país, o processo de ocupação da última grande fronteira agrícola do país - a Amazônia brasileira, ${ }^{3}$ começou a "ganhar forma”.

A partir de 1964, os governos militares, almejando a continuidade do processo de integrar a Amazônia à economia nacional e, com o intuito de atenuar a crise na economia rural que se acentuava principalmente nas regiões Sul, Sudeste e Nordeste, voltaram-se para a ampliação de políticas públicas que pudessem concretizar o processo de ocupação territorial da Amazônia. Para tal finalidade, foram criados órgãos específicos, que coordenavam a instalação e implantação de projetos que visavam à expansão da região, os quais incentivam a aquisição de terras e, com isto, promoviam o deslocamento de um grande número de trabalhadores/colonos migrantes.

Neste contexto, o surgimento da cidade de Sinop, localizada na região Norte de Mato Grosso, encontrava-se nesse processo de ocupação da Amazônia do final do século XX. Trata-se de uma cidade fruto de uma colonização privada, liderada pela empresa que deu origem ao nome da cidade: Colonizadora Sinop S/A - Sociedade Imobiliária do Noroeste do Paraná. A Empresa citada, beneficiada pelos incentivos fiscais pela parceria do Estado Federal, responsável por toda infraestrutura necessária e pelas políticas e órgãos criados para acelerar o processo de colonização, adquire uma extensa área de terra denominada posteriormente de Gleba Celeste ${ }^{4}$, onde seria então, iniciado um novo projeto de colonização, no qual Sinop estaria inclusa como uma das cidades da Gleba.

\footnotetext{
${ }^{2}$ A Marcha para Oeste foi uma política do governo de Vargas, nascida em 1943, a qual incentiva as pessoas a migrar para a região central do Brasil, na perspectiva de ocupar os "espaços vazios" do país, garantir a segurança das fronteiras e gerar riquezas.

${ }^{3}$ Os nove estados que compõem a Amazônia Brasileira são: Acre, Rondônia, Amazonas, Pará, Mato Grosso, Roraima, Amapá, Tocantins, e Maranhão (PICOLI, 2005, p. 17).

${ }^{4} \mathrm{~A}$ extensão de terra adquirida pela empresa colonizadora equivalia a aproximadamente 645.000 hectares. Denominada de Gleba Celeste, onde seria então dado início ao projeto de colonização das cidades de Sinop, Vera, Carmem e Cláudia.
} 
Figura 1 - Mapa do estado de Mato Grosso - localização de Sinop.

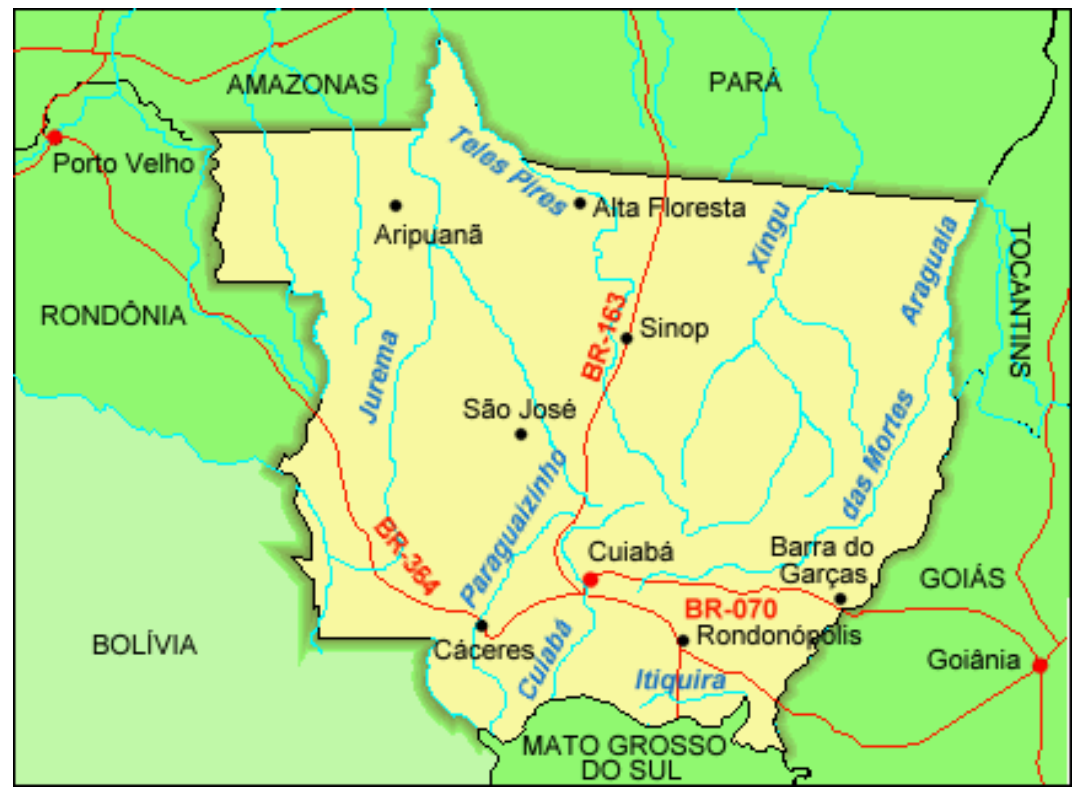

Fonte: Só Geografia, acervo particular, 2017.

Deste modo, a Gleba Celeste foi um projeto de Colonização privada, de propriedade da Colonizadora Sinop S.A., conforme Portaria do INCRA N ${ }^{\circ}$ 1.553/19722, que pertencia ao município de Chapada dos Guimarães, estado de Mato Grosso.

Neste cenário, Guimarães Neto (2002, p. 88) explica que sob o discurso da necessidade de "ocupação nacional do espaço amazônico, o empresariado iria apropriarse de grandes extensões de terras, assim como usufruir dos benefícios financeiros". Com isto, "a estratégia política para o controle das terras favorecia nitidamente a colonização particular, incumbida de desenvolver a região". Assim, no âmbito dessa política, segundo a mesma autora, as regras estavam dadas: a colonização não deveria limitar-se à ação governamental.

Contudo, reiteramos que esse projeto de colonização teve grande apoio dos governos federais e estaduais, e foram eles os maiores responsáveis pela efetivação da colonização das chamadas ‘áreas de fronteira', segundo Teixeira (2006):

A expansão da fronteira se constituía, para o Estado, num meio de garantir a posse do território e de controlar sua população. Desse modo, ao longo de toda a história do Brasil, o processo de ocupação se deu por etapas que "obedeciam" um movimento de leste para oeste, 
impulsionado pela produção de matérias-primas voltadas para o mercado externo. (TEIXEIRA, 2006, p. 13)

Ainda, de acordo com a autora supracitada, esse processo de ocupação da região trouxe um significativo crescimento econômico, entretanto, causou grandes impactos sociais e ambientais não só na área e seu entorno, mas também causou transformações na dinâmica econômica e espacial de outros estados do país.

Neste sentido, enfatizamos com Souza (2012) que a colonização em terras públicas tinha como objetivo reocupar com migrantes pobres a Amazônia Meridional. As grandes áreas da fronteira agrícola da Amazônia mato-grossense foram empregadas para acomodar a população excedente do processo de modernização do Centro-Sul do Brasil. E neste cenário, "o processo de reocupação, com recursos públicos, executado de forma predatória, provocou uma transformação social e ambiental radical na Amazônia matogrossense" (SOUZA, 2012, p. 129).

Atualmente, a terra no Norte de Mato Grosso, em sua grande extensão, está ocupada por pastagens e por imensas áreas cultivadas com soja, algodão e milho (BARROZO, 2010).

\section{A primeira instituição escolar de Sinop-MT: Escola Nilza de Oliveira Pipino}

A primeira escola de Sinop surgiu a partir do desejo dos próprios migrantes de possibilitar que seus filhos pudessem continuar tendo acesso à escola, uma vez que a educação era também apresentada nas propagandas que os atraíram, entretanto, quando na localidade chegaram não havia escola; esta era, entre tantas outras, mais uma promessa da Empresa Colonizadora. Os colonizadores, neste contexto, eram cientes de que os migrantes sulistas tinham na educação um referencial de futuro, entendiam que para os migrantes "a escola fazia parte da sua cultura, que "mandar" os filhos para a escola era uma obrigação da família, e, portanto, caberia aos pais fazê-lo" (PERIPOLLI, 2002, p. 121, grifo do autor). Nas palavras da ex-professora Anísia Mendes Gobbo (Depoimento 2012), "mesmo os pais vindo para aquele fim de mundo, (...) eles queriam ver seus filhos estudando (...) a educação era o futuro". 
Assim, utilizando-se desta concepção do que representava a educação para aquelas pessoas, a Empresa Colonizadora anunciava em suas propagandas além da terra farta, "que tudo dava" também a promessa da escola aos filhos:

O Seu Ênio, quando recebia as pessoas na Colonizadora para comprar terras, ele fazia propagandas, (...), ele falava muito sobre educação, sobre a escola. Para seu Ênio a escola era tudo, então ele incentivava muito as pessoas que vinham aqui, ele falava: "Não, pode vir, seu filho vai ter escola, vai estudar." Ele prometia muito escola, então o pai já vinha ciente de que o filho não ia ficar sem estudar. (PAULA, 2012)

Desta forma, fica explícito em nossas pesquisas que a Empresa Colonizadora, utilizava-se da Educação como ferramenta fundamental para atrair e fixar os migrantes, que deixavam suas terras de origem para residir em Sinop e em toda a Gleba Celeste. A estratégia de oferecer educação aos migrantes era a garantia de "dar" aos filhos dos colonos a continuação dos estudos e, assim, facilitar a decisão de migrarem para uma região desconhecida, onde tudo estava para se construir, inclusive o sistema educacional que, até então, não existia.

Deste modo, organizados, os pais construiriam uma pequena sala de aula de madeira, com poucas condições físicas e materiais - "Tudo começou naquela salinha de chão batido, de madeira, quatro paredes, janela e porta e mais nada, sem livros, sem materiais, com tantas dificuldades [...] não tinha nada!” (GUERRA, 2012).

A primeira professora, também escolhida pelos próprios migrantes, era a que naquele momento possuía maior instrução escolar. Esta tinha estudado até a $6^{\mathrm{a}}$ série do $1^{\circ}$ grau no estado do Paraná, e, por insistência dos pais migrantes, atendeu ao chamado para se tornar a professora da pequenina escola que começava a surgir, sendo uma extensão primeira da Escola N. Senhora Do Perpétuo Socorro, da cidade de Vera, colonizada pela mesma empresa, localizada a 80 quilômetros de distância de Sinop. Nas recordações da primeira professora, Terezinha Pissinati Guerra (Depoimento, 2012), “os pais começaram a pressionar a colonizadora, os próprios migrantes começaram a correr

\footnotetext{
${ }^{5}$ Palavras utilizadas pela professora Terezinha Pissinati Guerra (Depoimento 2012) ao se referir em seu depoimento às propagandas feitas pela Colonizadora em relação à promessa da terra fértil.
} 
atrás, eles diziam: 'vamos fazer a escola', 'quem faz o quê', 'quem vai dar aula', 'precisamos arrumar professor"'.

A educação em Sinop, assim como nas demais cidades da Gleba Celeste, teve forte influência da Empresa Colonizadora e da Igreja Católica, através das irmãs da Congregação Santo Nome de Maria, trazidas pelos colonizadores da cidade de Maringá Paraná, do Colégio Santo Inácio. Em Sinop e nas demais cidades da Gleba, as irmãs católicas eram responsáveis por direcionar os trabalhos sociais, de saúde e educacionais. Na educação, as irmãs tanto exerciam a docência quanto à gestão decidindo, juntamente com o Colonizador Ênio Pipino, as questões escolares (sejam no interior da escola, nas festividades e até mesmo na escolha dos cursos técnicos, conforme currículo estabelecido pela legislação da época ${ }^{6}$ ).

Tais apontamentos são importantes para apresentar que interesses eram intrínsecos à educação naquele momento inicial: em meio a tantas dificuldades de sobrevivência, em um lugar desconhecido, expostos aos perigos da floresta, à falta de subsídios de todos os gêneros, além da saudade dos amigos, parentes e da própria terra natal, as chances de que os migrantes retornassem aos seus lugares de origem eram grandes. Deste modo, a escola, assim como a Igreja, serviam como instrumentos que alimentavam o sonho daquelas pessoas: a escola representava o sonho do futuro melhor aos filhos e a Igreja era o lugar da fé, o lugar de confortar os sentimentos, as esperanças daquelas pessoas para que tivessem "força” para naquele local permanecer.

Dessa maneira, a não fixação do migrante naquelas terras significava o risco de fracasso do projeto de colonização, e, não era este o objetivo do Governo Federal, que intencionava, sobretudo, agregar aqueles espaços à economia nacional, além disso, a não fixação naquele espaço representaria a volta daquelas pessoas a suas terras natais, não resolvendo, deste modo, os problemas e conflitos de terras nos seus estados de origem. Ainda, o fracasso do processo colonizatório não fazia parte dos planos da empresa colonizadora, que queria o êxito do "negócio" que tivera feito.

Neste contexto, a escola promovia a fixação do colono, do migrante trabalhador. E, assim, se constituiu a primeira escola de Sinop - partindo inicialmente da iniciativa dos

\footnotetext{
${ }^{6} \mathrm{O}$ currículo escolar seguia a Lei Federal n. ${ }^{\circ} 5 \cdot 692 / 71$, que dispunha sobre a Reforma do Ensino de $1^{\circ}$ e de $2^{\circ}$ graus.
} 
migrantes, com auxílio material da empresa colonizadora para a construção física da instituição, qual foi posteriormente autorizada seu funcionamento pelo Governo do Estado de Mato Grosso, permanecendo a princípio vinculada à Escola N. Senhora do Perpétuo Socorro, da cidade vizinha de Vera-MT e posteriormente oficializada através do decreto $n^{\circ} 767 / 76$ de outubro de 1976 como Escola Nilza de Oliveira Pipino, primeira escola de Sinop-MT.

Figura 1- Escola construída pela Colonizadora Sinop- Extensão da Escola N. Sra. do Perpétuo Socorro de Vera - MT, 1974.

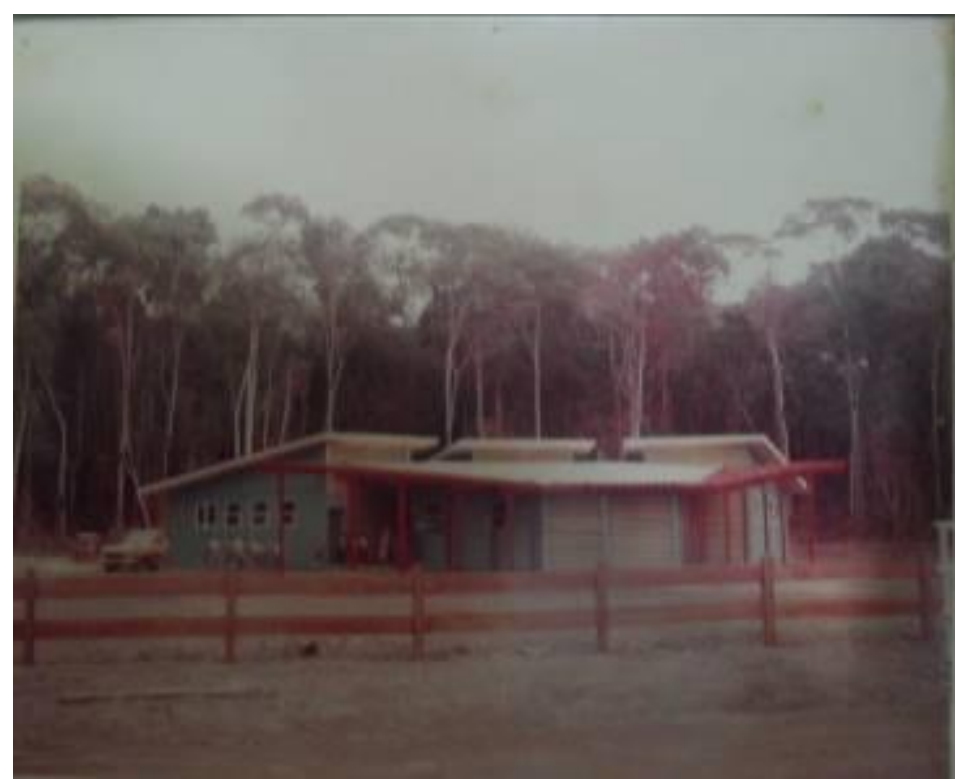

Fonte: Museu Histórico de Sinop.

Neste contexto, partimos do pressuposto de que a educação no período colonizatório de Sinop assumia um caráter religioso, uma educação fundamentada pelos princípios cristãos da Igreja Católica e, que além do caráter religioso, a escola não deixava de estar a serviço do Estado, atendendo à predominância de um ensino técnico voltado para o trabalho e para manter o civismo, a ordem, características da década de 1970, impostas pelo Regime Militar. Além disso, a escola atendia também aos interesses da Colonizadora privada, o que caracterizava desta forma, um trabalho conjunto e determinante na educação, desenvolvido pela Igreja, pelo Estado e pela empresa Colonizadora. 


\section{A escolarização da Infância no processo de colonização}

Para entendermos o processo de escolarização da escola pesquisada durante a temporalidade em estudo, nos utilizamos de grades curriculares, diários de classe, caderno de planejamento de professor, cadernos de ex-alunos e depoimentos orais. Neste âmbito, delineando a organização escolar durante o processo de colonização da primeira Escola de Sinop, Nilza de Oliveira Pipino, pôde-se constatar como estava organizado o ensino primário:

\section{Quadro 1}

Organização Curricular de $1^{\mathrm{a}}$ a $4^{\mathrm{a}}$ séries do $1^{\circ} \mathrm{Grau}(1973-1979)$

\section{$1^{\mathrm{a}}$ a $4^{\mathrm{a}}$ séries do $1^{\circ} \mathrm{Grau}$}

\section{Comunicação e Expressão}

Iniciação à Ciência

Integração Social/ Estudos Sociais

Fonte: Escola Nilza de Oliveira Pipino.

Conforme depoimento sobre a estrutura curricular, podemos pontuar também que "tinha as disciplinas do currículo e a gente também trabalhava Arte, Ensino Religioso, uma Educação Física, trazia outras coisas, se não fica cansativo para os alunos" (PAULA, 2012).

De acordo com os diários de classe analisados, os cadernos de ex-alunos pôde-se constatar um ensino no qual a prática da repetição e memorização imperava, um ensino tecnicista como estabelecido pelo modelo da época, voltado para o silêncio das vozes, silêncio dos pensamentos e de toda e qualquer ação que não fosse aquela estabelecida por um método pedagógico de muito rigor e punição.

Os conteúdos escolares destacavam o civismo, o amor à Pátria - a “ordem e progresso", além de inculcar valores morais, cristãos e sentimentos voltados para trabalhar, que enfatizassem o "ganha pão"7 de cada dia, de modo a preparar a criança

\footnotetext{
${ }^{7}$ Em um caderno de planejamento da $2^{\mathrm{a}}$ série de uma professora de 1976, da disciplina de Estudos Sociais, encontramos a expressão "ganhar o pão de cada dia", no qual constava o plano de trabalho a ser
} 
para o trabalho, para a obediência civil, para a convivência na sociedade e também na Igreja.

A fim de ressaltar tal discussão às fontes compulsadas na escola, destacamos um exemplo de um Diário de Classe da $4^{\mathrm{a}}$ série do $1^{\circ} \mathrm{Grau}$, da Disciplina de Integração Social, no qual o conteúdo registrado do $1^{\circ}$ Bimestre se restringe a inculcar valores morais e cívicos:

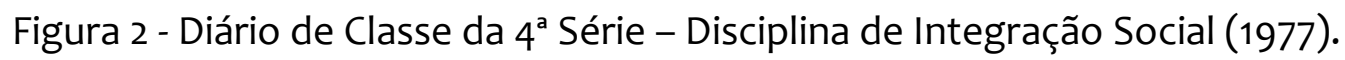

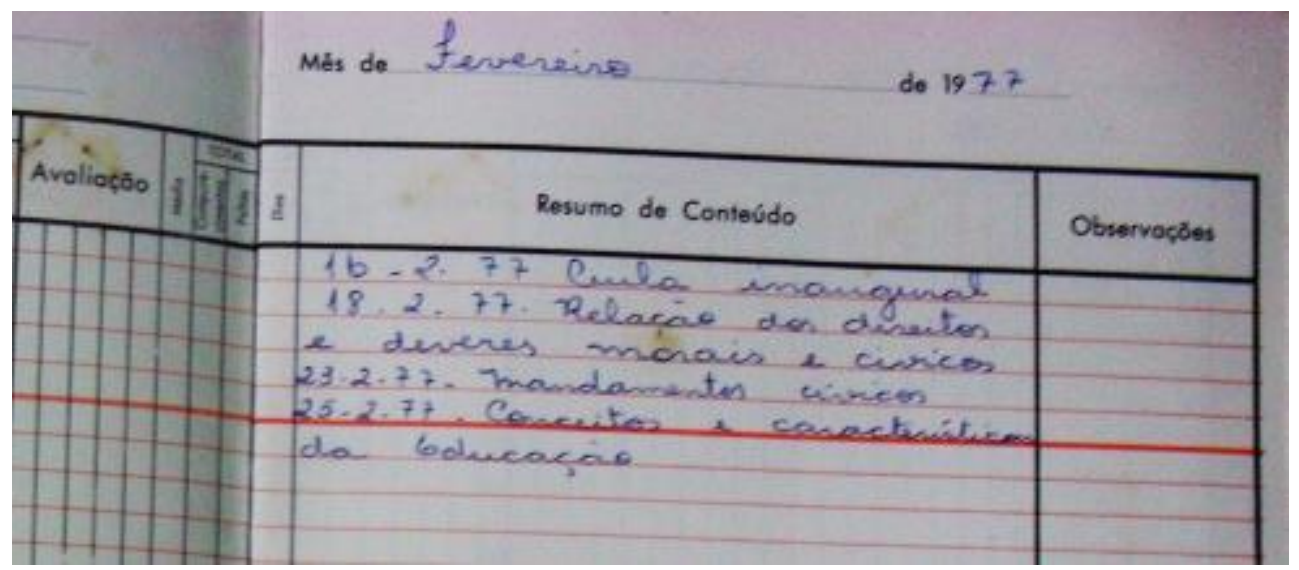

Fonte: Escola Nilza de Oliveira Pipino.

Também, dentre as práticas de escolarização nas séries iniciais, da $1^{\mathrm{a}}$ a $4^{\mathrm{a}}$ série do $1^{\circ}$ grau, foi possível verificar que as atividades trabalhadas eram compostas especialmente por "leituras silenciosas", cópias, ditados, tabuadas, as chamadas contas de 'arme e efetue', entre outros exercícios nos quais o aluno escrevia mecanicamente inúmeras vezes, letras, sílabas, palavras ou números, conforme recordado em alguns depoimentos:

Tinha muito ditado e cópia, se resumia muito em quadro e caderno então era copiar, copiar! Lembro nos ditados que se a gente errava alguma palavra, tinha de escrever ela inúmeras vezes, e, se durante a reescrita você errasse de novo, você escreveria tudo de novo muitas vezes [...]. Também tinha que saber a tabuada 'salteada', era um sofrimento, eu tremia! Você não sabia se você tremia porque estava com medo ou se era porque não sabia mesmo. (BÉRGAMO, 2012)

desenvolvido em determinado dia letivo, cuja a temática era "Os diferentes tipos de trabalho", que tinha como objetivo: "Levar o aluno a conhecer os diferentes tipos de trabalho e entender a importância do trabalho na vida das pessoas para poder ganhar o pão de cada dia” (Fonte: Museu Histórico de Sinop, 2011). 
Tinha leitura silenciosa. Ninguém podia nem respirar alto enquanto lia. $\mathrm{Na}$ matemática lembro até hoje das inúmeras continhas de arme e efetue e também tinha que escrever os números toda vez que terminasse alguma coisa para não ficar conversando. Eu costumava terminar antes as tarefas, então, logo tinha que escrever os números ou todo alfabeto, era uma maneira de ocupar todo o tempo do aluno e não deixar que ninguém conversasse. (PONCE, 2012)

A análise de alguns cadernos de ex-alunos da época também sinaliza para estas práticas, conforme os exemplos a seguir:

Figura 3 - Caderno de Aluno da $1^{\text {a }}$ Série (1976a).

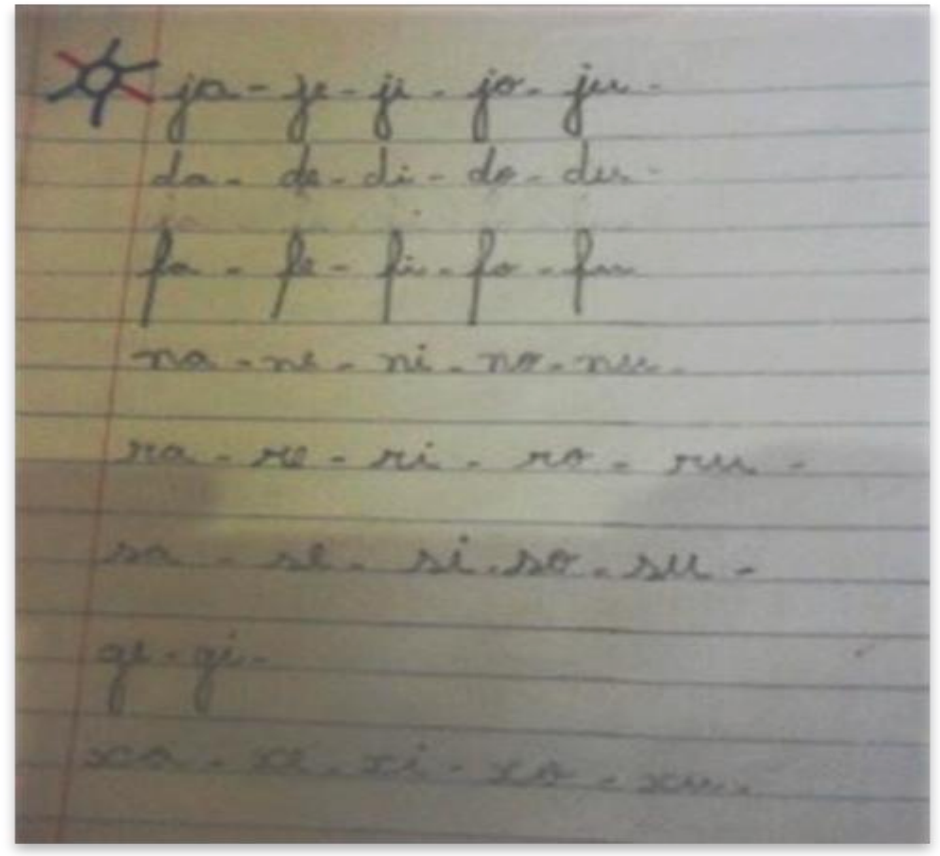

Fonte: Acervo Particular Ponce.

Figura 4 - Caderno de Aluno da $1^{\text {a }}$ Série (1976b)

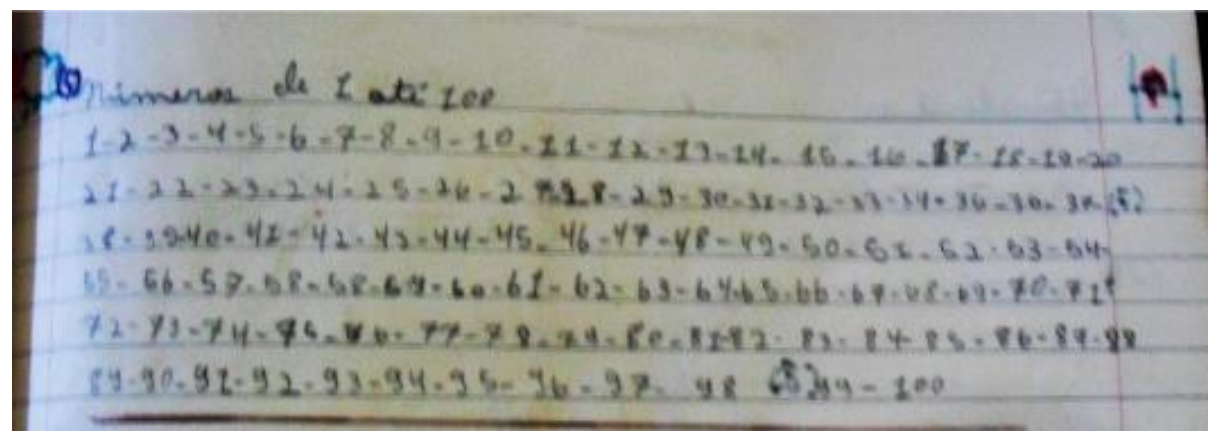

Fonte: Acervo Particular Ponce. 
Outra prática constatada era a cobrança da Leitura na $1^{\mathrm{a}}$ série do $1^{\circ}$ grau. Todos os alunos, ao final do ano letivo, eram submetidos à prova de leitura; as irmãs chamavam aluno por aluno para ler em voz alta e verificar se estavam aptos a serem aprovados para a $2^{\mathrm{a}}$ série, caso dominassem a leitura - "Todo mundo tremia no dia da prova da Leitura de frente com a Irmã Editha, que era a Diretora" (PONCE, 2012).

Outros exames também eram aplicados no decorrer do ano letivo a exemplo dos testes de tabuadas que eram exigidos com rigor e de forma muito abstrata, conforme relembra uma ex-aluna:

A coisa que mais me doía era o dia de tomar tabuada, eu decorava tudo mas, chegava na hora eu ficava nervosa e errava, era na frente dos outros e sempre tinha os que eram bons e os que eram ruins na tabuada, eu era ruim, todos riam quando a gente errava. A matemática era assustadora pra mim: aquele monte de números que eu não sabia para que serviam. (BERGAMO, 2012)

Assim, percebemos um ensino pouco efetivo e que muitas vezes ensejava ações que promoviam constrangimento entre os alunos e alunas da época. Além disso, desde os anos iniciais da escolarização, é possível detectar a supremacia da Língua Portuguesa e da Matemática no interior da Instituição de Ensino em análise.

Ainda, faz-se necessário pontuar, que conforme depoimentos obtidos, todos os dias antes de entrarem na sala de aula, os alunos ficavam em fila, em posição de sentido e, após cantar o hino, hastear a bandeira e fazer a oração diária, ouviam discursos pronunciados pela Irmã Editha, diretora da escola, os quais faziam alusões aos valores, normas e juízos que eram necessários ser mantidos na escola, na família e na sociedade.

Diante do exposto, inferimos que a educação em Sinop durante o processo de colonização, teve forte presença e influência da Colonizadora e da Igreja, as quais buscavam atender os propósitos nacionais de uma política social fundamentada pela ideologia tecnicista, de instrumentalização para o trabalho, para agir de forma "servil" e obediente na sociedade, para que assim atendessem às expectativas do Estado, daquilo que o Regime Militar solicitava da educação, o que torna óbvio que a seleção e a produção do conhecimento sempre estiveram fartas de intencionalidades e intimamente 
ligadas às necessidades e interesses "políticos" (GODSON, 2008). Assim, de acordo com o discurso nacional, era preciso adequar a escola para esses fins - era necessário preparar desde a infância os cidadãos para que se tornassem futuros trabalhadores habilitados a receber um país em acelerado crescimento econômico/industrial que dependeria de muita "mão de obra".

\section{O Brincar: as táticas adotadas pelas crianças para driblar a vigilância da escola}

Compreendemos na cultura infantil, produzida pelos sujeitos da instituição pesquisada, a possibilidade de concebermos a história de um cotidiano marcado pela criação, invenção daquilo que os sujeitos faziam com os produtos que lhes eram fabricados (CERTEAU, 1998). No cotidiano escolar, as estratégias de práticas intencionais estavam em conflito com as táticas de subversão e a escola, bem ou mal, lidava com este processo de conflito, pois era impossível manter rigorosamente tudo à maneira que lhe convinha, fazendo-se presentes as práticas desviantes que fugiam, escapavam às normas e, muitas vezes, talvez na maioria delas, não eram percebidas, ou simplesmente eram vistas como banais, rotineiras, sem "periculosidade" ${ }^{\text {. }}$

O Estado, a Igreja, a Colonizadora tinham como concepção que a escola era o cenário ideal para a formação da massa, aliás, ideia ainda difundida na contemporaneidade. Contudo, tal modelo de controle disciplinador que se intentava impor à escola em análise não contava que teria de lidar com os modos insistentes da cultura como criação humana, com as práticas diferenciadas de apropriação desses modelos, os quais resistiam sutilmente, “dobravam-se sem quebrar" (AZEVEDO; ARAÚJO, 2011) e, que então, reinventavam aos seus modos o sentido de estar naquele meio - dito por Certeau (1998), podem ser explicadas enquanto táticas, encontradas por aqueles sujeitos para serem usadas como suas armas de combate - $a$ arte do fraco, que "[...] fingia obediência aos poderes estratégicos, mas não se iniciava uma guerra explícita contra esses" (AZEVEDO; ARAÚJO, 2011, p. 483). ${ }^{9}$

\footnotetext{
${ }^{8}$ Sobre estes estudos ver Rohden (2012).

${ }^{9}$ Idem.
} 
Devido à metodologia tradicional que se configurava em sala de aula, percebemos, a partir das fontes analisadas e dos depoimentos colhidos, que, aparentemente, os alunos eram obedientes, silenciosos e servis, mesmo porque a comunidade em que viviam se comportava dessa forma, refletindo diretamente no espaço escolar. Por outro lado, um repensar sobre todo esse "controle disciplinador" criado para formar os cidadãos nos moldes que se eram exigidos, é possível perceber as marcas de um cotidiano em que as crianças recriavam o lugar em momentos imperceptíveis, em simples situações consideradas banais, ordinárias.

Muitas histórias que desfaziam a ordem estabelecida compunham o cotidiano da escola, em especial das crianças que ali frequentavam e portanto, produtoras de culturas infantis naqueles espaços e tempos analisados. E aqui, faz-se necessário um parêntese para enfatizar que "as culturas da infância transportam as marcas dos tempos, exprimem a sociedade nas suas contradições, nos seus estratos e na sua complexidade" (SARMENTO, 2003, p. 4).

Para tanto, entendemos como peculiar a cultura infantil, percebendo que ela se configura de acordo com cada tempo e espaço, e, é tecida dentro de cada sociedade, de modo singular. Contudo, a cultura infantil em análise neste estudo, destaca que mesmo diante da ordem, da disciplina da época, da imposição de valores e normas, havia movimentos que desconfiguravam a ordem dominante, entendida por Certeau (1998) como as táticas que moviam os sujeitos nas suas artes de fazer, imprecisas, sem localização exata, surgidas das contingências da situação, de modo a aproveitar as lacunas do lugar da ordem, fruto da "[...] inteligibilidade criada no aqui e agora, exigindo inteligência viva, parecendo desprezar modelos preestabelecidos, estando constantemente apreendendo a situação e agindo sobre ela improvisando saídas" (AZEVEDO; ARAÚJO, 2011). Para fomentar esta análise, trazemos para o debate algumas vozes dos sujeitos de pesquisa:

Devido a tanta imposição de disciplina, tinha muita gente que tinha muito medo das irmãs, principalmente os meninos que faziam muita bagunça. Tinha uns que levavam reguada das professoras, mas não adiantava. Ficavam de castigo no milho, tinha que colocar o joelho em cima do milho e não adiantava [...] (PONCE, 2012) 
A brincadeira do elástico era a preferida, mas teve uma época que as irmãs proibiram porque diziam que era perigoso, mas sempre alguém dava um jeito de levar. Também jogávamos bola apesar das irmãs não gostarem muito para não entrar na sala suados, mas a gente brincava por mais que fosse pouco tempo, aproveitava aquele tempinho para brincar. A gente construía brinquedos, fazia bola de meia para arremessar no palhaço, era sempre a criatividade da gente, porque não tinha outras coisas. (SILVA, 2012)

Nesses depoimentos, percebemos que existia, sim, o "medo" da punição, mas em oposição se revelava o jogo, a "malícia inocente" que vencia todo e qualquer receio e encontrava nas "fugas" maneiras de abrir feridas, provocando deste modo, a "[...] mobilidade, mas numa docilidade aos azares do tempo, para captar, no voo, as possibilidades oferecidas por um instante [...]” (CERTEAU, 1998, p. 100), as astúcias, golpes, táticas, artimanhas se faziam presentes, em detalhes, em artes de fazer.

Neste sentido, compreendemos com Sarmento (2003, p. 05) que "quer a cultura escolar, [...] só se consegue transmitir e difundir de modo sucedido quando se compatibilizam com as condições específicas de recepção pelas crianças." Ou seja, como reitera Certeau, em A invenção do Cotidiano (1998), o modo como os sujeitos incorporam os produtos que para eles lhe são fabricados nem sempre atingem os objetivos para quem os criou na tentativa de manipulá-los - há um jogo de táticas versus estratégias.

Diante disto, corroboramos com Sarmento (2003, p. 07) que "entre as formas culturais produzidas e fruídas pelas crianças, consideraremos fundamentalmente os jogos infantis [...]" assim, pontuamos o brincar como produção cultural e, espaço formativo e educativo, como uma prática da experiência. Experiência, aqui concebida numa perspectiva benjaminiana (1987), como algo que perpassa o tempo, que transgride do instante único vivido do jogo, do brinquedo e da brincadeira.

Com isto, nosso olhar neste trabalho para a História da Infância reconhece, sobretudo, a criança como produtora de uma cultura específica. E, a experiência cultural do brincar se configura como cenário de tal construção histórica, social e cultural. Era nas relações do brincar e entre seus pares que a criança constituía seu mundo, num mundo 
maior, como diria Benjamin (2009). E, o tempo destinado na escola - o recreio, por mais que fosse curto ${ }^{10}$, era momento da criança viver esta “constituição de seu mundo":

O horário do recreio era o horário de brincar e de comer o lanche. Não era recreio dirigido, então a gente aproveitava para brincar bastante, de correr, mas a irmã não gostava muito porque suava, mas o pátio era grande, ela nem via. Também gostávamos de brincar de 3 mocinhas da Europa: lembro-me ainda hoje: Somos 3 mocinhas da cidade. O que vieram fazer? Muitas coisas! Então faz para nós ver! Então isto era o que mais nós gostávamos de fazer! [...] Brincávamos muito de roda: de Terezinha de Jesus, passava o recreio rodando, tinha aquela cantiga: $A$ menina que tá na roda: A menina que tá na roda, é uma gata espichada, tem a boca de jacaré e a saia remendada! Depois, trocava, ia outra criança no meio. Fazíamos muita brincadeira de roda, eram momentos maravilhosos! (PONCE, 2012)

E assim, aproveitando-se do tempo sem "vigilância" as crianças brincavam, inventavam, criavam, imaginavam, constituíam mil e uma artes de fazer. Contudo, produziam cultura, se faziam autores/as de suas próprias histórias. Neste sentido, compreender historicamente o brincar como produção cultural e social da criança, é conceber a infância de modo a atribuir-lhe identidade própria daquilo que lhe é inerente daquilo que Benjamin (2009) explica que não é preciso nenhum adulto ensinar à criança: que se faz no mundo do brincar.

Benjamin (2009), em seus textos sobre a infância, traz a imagem da criança como uma especialista em brincar com as sobras e os restos do mundo adulto ao dizer que elas se sentem:

[...] irresistivelmente atraídas pelos detritos que se originam da construção, do trabalho no jardim ou em casa, da atividade do alfaiate ou do marceneiro. Nesses produtos residuais elas reconhecem o rosto que o mundo das coisas volta exatamente para elas, e somente para elas. Neles, estão menos empenhadas em reproduzir as obras dos adultos do que em estabelecer entre os mais diferentes materiais, através daquilo que criam em suas brincadeiras, uma relação nova e incoerente. Com isso as crianças formam o seu próprio mundo de coisas, um pequeno mundo inserido no grande. (BENJAMIN, 2002, p. 104)

\footnotetext{
${ }^{10}$ De acordo com depoimentos orais, o tempo destinado ao recreio de $1^{\mathrm{a}}$ a $4^{\mathrm{a}}$ séries do $1^{\circ}$ grau era de quinze minutos.
} 
Esta dimensão criadora, colocada por Benjamin, também está presente na vida das crianças do tempo de infância, sujeitos desta pesquisa, uma vez que naquele tempoespaço histórico, a natureza fornecia os instrumentos para fabricar brinquedos, para inventar brincadeiras, criar personagens. Era de restos, de pedaços de pau, latas, que as crianças em tal momento e contexto se utilizavam, e, não faziam apenas como mera imitação do mundo adulto, mas recriavam, inventavam, e, desta forma produziam cultura (CORSARO, 2011):

A gente brincava com o que tinha, eram sobras de madeira, restos de qualquer coisinha. Brincar era a melhor coisa que tinha naquela floresta gigantesca. Para nós era o momento de liberdade e naqueles cipós nós éramos puro Tarzans! (BÉRGAMO, 2012)

Com isso, se fazia uma cultura criada e recriada no espaço escolar, entre trocas, encontros, situações conflituosas, práticas desviantes, não planejadas e muitas vezes ignoradas, em que imperava o silêncio, mas também sutilmente ressoavam as vozes que cantavam juntas cirandas e cantigas de roda (ROHDEN, 2012).

Nas palavras de Walter Benjamin:

As crianças formam o seu próprio mundo de coisas, um pequeno mundo inserido no grande. Dever-se-ia ter sempre em vista as normas desse pequeno mundo quando se deseja criar premeditadamente para crianças e não se prefere deixar que a própria atividade - com tudo aquilo que é nela requisito e instrumento - encontre por si mesma o caminho até elas. (BENJAMIN, 2009, p. 104)

Diante do exposto neste trabalho, entendemos a criança com um ser ético, político-social, produtor de história e de cultura, que mesmo diante das regulações da família, da escola, interpretam de modo criativo, aos seus modos, a cultura dos adultos, reinventando-a, produzindo uma cultura específica entre seus pares (CORSARO, 1992).

Nossa intenção é demarcar o papel da infância enquanto produtora de história, de cultura, e neste contexto, Corsaro (2011) nos auxilia neste trabalho a compreender que as crianças produzem cultura entre seus pares e com os adultos, ou seja, a criança não apenas imita ou reproduz algo, mas cria, recria, reinventa atribuindo novos significados às 
ações que lhe são apresentadas, no contexto social que estão inseridas. Nas palavras de Corsaro (2011, p. 29): “as crianças não se limitam a internalizar a sociedade e a cultura, mas contribuem ativamente para a produção e mudança culturais". No entanto, analisando a História da Infância no momento da colonização de Sinop, é importante salientar que as crianças tiveram, sim, um relevante papel social, cultural e histórico em tal lócus e período investigado ou seja, ocasião em que tanto a cidade como a escola se constituíam, entretanto, tal passado não nos é apresentado, dificultando a visibilidade da criança em tal sociedade. Contudo, trata-se de um desafio que a História da Infância precisa de forma emergente destacar, a fim de consolidar o papel cultural e social das crianças no passado, seja ele num passado recente, seja ele através dos séculos.

\section{Reflexões finais}

Este trabalho teve como propósito direcionar um olhar histórico da Infância, de forma a sinalizar para uma questão emergente na História da Educação no que diz respeito ao papel cultural e social da criança no passado, entendida desta forma como ator social, sujeito produtor/a de cultura e história.

Para tal, fundamentando-nos em Michel De Certeau (1998), reconhecemos na produção das crianças, sujeitos da instituição escolar analisada, a possibilidade de concebermos a história de um cotidiano caracterizado pela criação, invenção daquilo que os sujeitos faziam com os produtos que lhes eram fabricados. Desta forma, estratégias de práticas intencionais estavam constantemente em conflito com táticas de subversão no interior da escola.

Finalmente, intentou-se ampliar o debate ao que se refere a produção cultural da infância, de modo a compreender que as crianças apropriam-se criativamente da informação do mundo adulto para produzir sua própria cultura de pares, apropriação esta que, segundo Corsaro (1992-2011) e Sarmento (2003), é um processo criativo de reprodução interpretativa e, não meramente por uma questão de simples imitação.

Diante disto, na documentação encontrada, nos diversos depoimentos orais coletados e nas fontes iconográficas, documentos e cadernos escolares, foi possível 
perceber as marcas de um ensino em que as atividades estimulavam a memorização e a repetição, em que o silêncio predominava na sala de aula, em que a Pátria era exaltada todos os dias na tentativa de "docilizar" mentes e corpos; uma educação embasada na religião, cujos princípios inculcavam valores e juízos morais, enaltecendo com "glórias" a "nova" cidade, com o intuito de apresentar na fé o refúgio de consolação e a esperança de dias melhores.

Contudo,no que se refere ao modelo de controle instituído na escola para disciplinar, silenciar - “[...] uma prática panóptica a partir de um lugar de onde a vista transforma as forças estranhas em objetos que se podem observar e medir, controlar, portanto, e 'incluir' na sua visão [...]”' (CERTEAU, 1998, p. 100), havia também, na dinâmica da sala de aula, o movimento das crianças enquanto sujeitos da história, possibilitando uma produção cultural específica, na qual os “fracos” jogavam sutilmente com os "fortes" (CERTEAU, 1998), sem entrar em confronto direto, sem ser necessária a imposição dos "fracos", mas aos seus modos, aos seus jeitos de fazer e com suas mobilidades táticas fazendo aparecer suas artes de fazer, conseguiam estar onde ninguém esperava, mobilizando as estratégias do forte, fazendo daquele lugar um espaço, tornando-o, então, um lugar praticado - lugar que movia-se, lugar que se escondia e aparentemente dominado, porém conquistado, recriado e transformado em espaço no mundo (CERTEAU, 1998, p. 101) daqueles que nele habitavam.

O ensejo neste trabalho é iniciar uma caminhada para um olhar para a História da Infância, que conceba as crianças como coautoras da história, participantes ativas na construção da cultura juntamente com os adultos e entre seus pares, de forma a possibilitar a visibilidade social da criança na história e seu papel na sociedade. 


\section{Referências}

ALBUQUERQUE, Andréa Serpa. Cultura escolar em movimento: diálogos possíveis. Rio de Janeiro: EdUFF, 2006.

ARIÈS, Philippe. História social da criança e da família. Rio de Janeiro: J. Zahar, 1981.

AZEVEDO, Fernando Antônio Gonçalves; ARAÚJO Clarissa Martins de. Meninos dos sinais e a arte de inventar o cotidiano: personagens hostis ou hostilizados na Grande cena da(s) cidade(s). In: ENCONTRO NACIONAL DA ASSOCIAÇÃO NACIONAL DE ARTES PLÁSTICAS, $20^{\circ}$, 2011. Rio de Janeiro. Anais... Rio de Janeiro: Anpap, 2011, p. 477-489. Disponível em: <http://www.anpap.org.br/anais/2011/pdf/ceav/fernando_antonio_goncalvez_de_azeved o.pdf> Acesso em: 08/02/2012.

BARROZO, João Carlos (Org.). Mato Grosso. A (re) ocupação da terra na Fronteira Amazônica (século XX). São Leopoldo/RS: Oikos, Unisinos; Cuiabá/MT: EdUFMT, 2010.

BRASIL. Lei 5692/71, de 11 de agosto de 1971. Lei Federal da Educação Nacional, 1971.

BENJAMIN, Walter. Magia e técnica, arte e política: ensaios sobre literatura e história da cultura. v. 1. Trad. Sérgio Paulo Rouanet. 3 ed. São Paulo: Brasiliense. (Obras Escolhidas). 1987.

BENJAMIN, Walter. Reflexões sobre a criança, o brinquedo e a educação. Tradução Marcus Vinicius Mazzari. 3. ed. São Paulo: Editora 34, 2009.

BERGAMO. Depoimento (oral). Sinop (Mato Grosso), 17 de Janeiro de 2012.

CERTEAU, Michel de. A invenção do cotidiano: artes de fazer. Tradução de Ephraim Ferreira Alves. 4. ed. Petrópolis: Vozes, 1998.

CORSARO, William A. Interpretative reproduction in children in peer cultures: Social Psychology. USA: Quarterly, 1992.

CORSARO, William A. Sociologia da infância. Tradução de Lia Gabriele Regius Reis. $2^{\mathrm{a}}$ ed. São Paulo: Artmed, 2011.

ESCOLA NILZA DE OLIVEIRA PIPINO. Organização curricular de $1^{\mathrm{a}}$ a $4^{\mathrm{a}}$ séries do $1^{\circ}$ grau (1973-1979). Acervo Público, Sinop, visita em 08 de dezembro de 2011.

ESCOLA NILZA DE OLIVEIRA PIPINO. Diário de classe da $4{ }^{a}$ Série: disciplina de Integração Social (1977). 1977. 1 fotografia color., 5,61 cm x 12, $97 \mathrm{~cm}$.

GUERRA, Depoimento (oral). Sinop (Mato Grosso), 25 de Janeiro de 2012.

GUIMARÃES NETO, Regina Beatriz. A lenda do ouro verde: política de colonização no Brasil contemporâneo. Cuiabá: UNICEN, 2002. 
GODSON, Ivor. Currículo: teoria e história. Tradução Atílio Brunetta. 10. ed. Petrópolis, RJ: Vozes, 2008.

JULIA, Dominique. A cultura escolar como objeto Histórico. Trad. Gisele de Souza. Revista Brasileira de História da Educação. Campinas: Autores Associados, $1^{\circ}$ Número, 2001, p. 944 .

MORIN, Edgar. Os sete saberes necessários à educação do futuro. Tradução de Catarina Eleonora F. da Silva e Jeanne Sawaya São Paulo: Cortez, 2004.

MATO GROSSO (Estado). Delegacia do Estado de Educação. Decreto n. 767 de 26 de Outubro de 1976: dispõem sobre a criação da Escola Estadual de $1^{\circ} \mathrm{Grau}$ Nilza de Oliveira Pipino. Palácio Paiaguás: Cuiabá, 1976.

MUSEU HISTÓRICO DE SINOP. Escola construída pela Colonizadora Sinop- Extensão da Escola N. Sr ${ }^{\mathrm{a}}$. do Perpétuo Socorro de Vera- MT, 1974. 1974. 1 fotografia color., 7,75 cm x $9,56 \mathrm{~cm}$.

PAULA. Depoimento (oral). Sinop (Mato Grosso), 02 de Fevereiro de 2012.

PERIPOLLI. Odimar José. Amaciando a terra - O projeto casulo: um estudo sobre a política educacional dos projetos de colonização do Norte de Mato Grosso. 2002. 182 f. Dissertação (Mestrado em Educação) - Universidade Federal do Rio Grande do Sul, Porto Alegre, 2002. Disponível em: <http://www.lume.ufrgs.br/handle/10183/2285>. Acesso em 25 fev. 2012.

PICOLI, Fiorelo. Amazônia: do mel ao sangue - os extremos da expansão capitalista. Sinop-MT: Fiorelo, 2005.

PONCE. Depoimento (oral). Sinop (Mato Grosso), 23 de Janeiro de 2012.

PONCE. Caderno da $1^{\text {a }}$ série, 1976a. 1 fotografia color., 9, $65 \mathrm{~cm} \mathrm{x} \mathrm{8,02} \mathrm{cm.}$

PONCE. Caderno da $1^{\mathrm{a}}$ série, 1976b. 1 fotografia color., 4,09 cm x $14 \mathrm{~cm}$.

ROHDEN, Josiane Brolo. A Reinvenção da escola: história, memórias e práticas educativas no período colonizatório de Sinop-MT (1973-1979). 2012. Dissertação (Mestrado em Educação) - UFMT Programa de Pós-Graduação em Educação, Cuiabá, 2012.

SARMENTO, M. J. Imaginário e culturas da infância. Cadernos de Educação, Pelotas, v. 12, n. 21, p. 51-69, 2003.

SILVA. Depoimento (oral). Sinop, (Mato Grosso), o7 de fevereiro, 2012.

SÓ GEOGRAFIA. Mapa estado de Mato Grosso. Disponível em: <http://www.sogeografia.com.br/Conteudos/Estados/MatoGrosso/ >. Acesso em: 27 mar. 2017. 
SOUZA, Edison Antônio de. MATO GROSSO: A (re) ocupação da terra na fronteira Amazônica. Estado e Políticas Públicas. Tempos Históricos. Marechal Cândido Rondon, v. 16, n. 2, p. 125-141, jul./dez. 2012. p. 127-144. Disponível em:

http://webcache.googleusercontent.com/search?q=cache:rWwGYNqIE-kJ:erevista.unioeste.br/index.php/temposhistoricos/article/download/8100/5993+\&cd=1\&hl=p $\mathrm{t}-\mathrm{BR} \& \mathrm{ct}=\mathrm{clnk} \& \mathrm{gl}=\mathrm{br}$. Acesso em 16/02/2016.

TEIXEIRA, L. A colonização no Norte de Mato Grosso: o exemplo da Gleba Celeste. 2006. 118 f. Dissertação (Mestrado em Geografia) - Universidade Estadual Paulista, Presidente Prudente, 2006.

Universidade do Estado de Santa Catarina - UDESC

Programa de Pós-Graduação em Educação - PPGE

Revista Linhas

Volume 19 - Número 40 - Ano 2018

revistalinhas@gmail.com 